\title{
EDITORIAL
}

\section{Fibrinolytic treatment for elderly patients with acute myocardial infarction}

\section{J M Estess, E J Topol}

Heart 2002;87:308-311

\begin{abstract}
Although fibrinolytic treatment of elderly patients is generally accepted, questions have been raised recently about its safety and efficacy.
\end{abstract}

F ibrinolytic treatment is the standard of care for eligible patients presenting early with acute ST segment elevation myocardial infarction (MI) to hospitals where rapid triage to primary angioplasty is unavailable. Although fibrinolytic treatment of elderly patients is generally accepted, ${ }^{1}$ a recent paper raised questions about its safety and efficacy. In this editorial, we will review the relevant studies and provide perspective on this controversy.

The observational study by Thiemann and colleagues was conducted using the Cooperative Cardiovascular Project (CCP) database of 210996 patients treated for acute myocardial infarction during February 1994 and July 1995. ${ }^{2}$ Patients were excluded if they had absolute contraindications to fibrinolytic treatment, left bundle branch block (LBBB), were admitted to hospitals with on-site angioplasty, transferred between hospitals or had other potential confounders for the administration of fibrinolytics. Patients $>86$ years of age (6156 patients) and those not receiving aspirin and/or heparin were also excluded. The final cohort consisted of 7864 patients, $48 \%$ of eligible patients aged 65 to 75 years, and $34 \%$ of eligible patients aged 76 to 86 . Greater than $70 \%$ of patients in both groups received tissue plasminogen activator ( $\mathrm{t}-\mathrm{PA}$ ) as the fibrinolytic agent, and all patients received aspirin and heparin. Among patients 65 to 75 years old the 30 day crude mortality rates were $6.8 \%$ for patients treated with fibrinolytic therapy compared to $9.8 \%$ in the control group. However, among patients $>75$ years of age, the 30 day crude mortality rate was $18.0 \%$ with fibrinolytic treatment versus $15.4 \%$ without treatment, resulting in a mortality hazard ratio of 1.38 . Thiemann and colleagues concluded that in a nationwide clinical practice, fibrinolytic treatment for patients $>75$ years of age is unlikely to confer survival benefit, and may have a significant survival disadvantage. How should we interpret the data which clearly contradicts previous randomised clinical trials, and a published meta-analysis supporting benefit among elderly patients? Does our current fibrinolytic strategy put certain groups of patients at increased risk?

\section{LARGE SCALE RANDOMISED TRIALS}

Several large scale randomised controlled trials $^{3-11}$ have included patients over 75 years old.
The numbers of elderly patients included in these studies are generally considered to be small and placebo versus fibrinolytic comparisons are limited, thus firm conclusions must be interpreted in that context. The first trials of fibrinolytic efficacy-GISSI- ${ }^{3}$, and ISIS- $2^{4}$ - included 2678 patients aged greater than 75 years and revealed a combined absolute benefit of 39/1000 patients treated with streptokinase (SK) compared to placebo $(p=0.02)$ (fig 1$)$. Neither study included routine heparin use, and only half of the patients in the ISIS-2 study received aspirin. The subsequent fibrinolytic therapy trialists (FTT) metaanalysis $^{12}$ of nine randomised placebo controlled trials, including a total of 5754 patients $>75$ years of age, revealed that while the relative risk reduction was less for patients $>75$ years of age, the absolute risk reduction was 10 lives saved per 1000 patients treated (odds ratio (OR) 0.94, 95\% confidence interval (CI) 0.84 to 1.07). This number was comparable to the absolute benefit seen in patients less than 55 years of age, although not statistically significant. The original FTT data included patients with ST depression only, T wave inversion, or presenting greater than 12 hours. These have been shown to be detrimental and are now considered uncertain or even contraindications for fibrinolytic treatment.

Using a conventional thrombolytic criteria (ST elevation or new LBBB presenting less than 12 hours) a more recent analysis of the FTT data shows that among patients $>75$ years of age, the absolute risk reduction was 34/1000 patients treated (OR 0.84, 95\% CI 0.72 to 0.98 ) (fig 2). A significant proportion of the patients from this earlier meta-analysis received streptokinase rather than $\mathrm{t}-\mathrm{PA}$, and some of the trials did not include a routine aspirin and heparin strategy.

The GUSTO-1 trial ${ }^{7}$ subsequently established the superiority of front loaded t-PA plus aspirin with intravenous heparin compared to streptokinase plus aspirin with either subcutaneous or intravenous heparin. This trial of 41021 patients included 4625 patients aged $75-85$ and 412 patients over the age of 85 years. Patients $<85$ years old showed a constant relative reduction in mortality, with an increasing absolute mortality reduction, but an increased relative and absolute

Abbreviations: aPTT, activated partial tissue thromboplastin; CCP, Cooperative Cardiovascular Project; FTT, fibrinolytic therapy trialists, GISSI, gruppo Italiano per lo studio della sopravvivenza nell'infarcto miocardico; ISIS, international study of infarct survival; LBBB, left bundle branch block; $\mathrm{Ml}$, myocardial infarction; $\mathrm{OR}$, odds ratio; SK, streptokinase t-PA, tissue plasminogen activator 


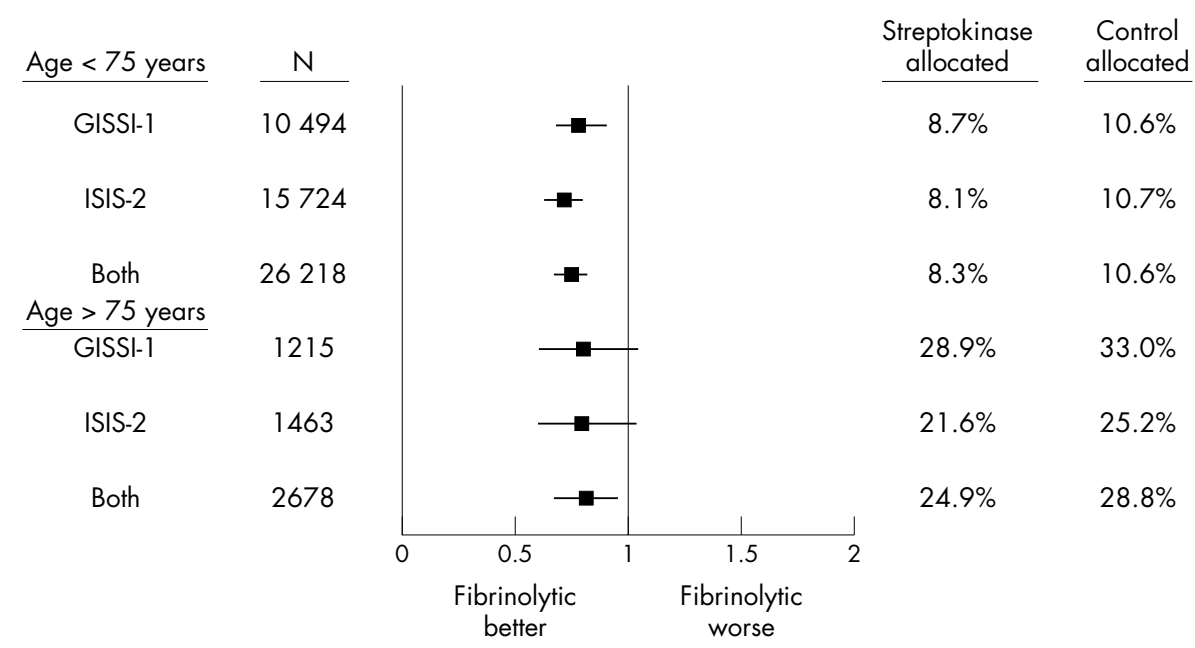

Figure 1 Absolute benefit with streptokinase (SK) versus conservative treatment by age in the GISSI-1 and ISIS-2 trials. Adapted from: The ISIS Collaborative group. Optimizing thrombolytic therapy of acute myocardial infarction: age is not a contraindication. Circulation 1991;84(suppl II):II-230 (with permission).

risk of stroke with accelerated t-PA versus SK as the age increased. This is an important observation supporting the tenet that more enhanced fibrinolytic treatment is even more effective in the elderly (to age 85). A net clinical benefit of 17 fewer deaths or disabling strokes per 1000 patients treated was seen in patients $75-85$ years of age (fig 3). Although 41021 patients were included in the GUSTO study, the data are underpowered to detect significant differences in benefit according to age. For patients $>85$ years old, interestingly the risk of stroke was higher, but the absolute mortality difference was lower in patients treated with SK plus subcutaneous heparin compared to accelerated t-PA. The sample size (412 patients) was small and the power to detect a significant difference with that sample size and event rate was only $0.20{ }^{13}$

A more recent observational study from the Swedish Register of Cardiac Intensive Care reported improved outcomes for fibrinolysis with SK versus conservative therapy in patients $>75$ years of age. Despite an increase in severe bleeding complications for patients $>75$ years of age, patients still did better with fibrinolysis. Among 5428 patients $>75$ years of age admitted with ST segment elevation or LBBB infarction, the combined end point of cerebral bleeding plus all cause mortality at one year was significantly better for fibrinolysis (38.3\% for treated patients $v 48.4 \%$ ) in the conservative group $(\mathrm{p}<0.001){ }^{14}$
A second observational study comparing fibrinolytic treatment to primary angioplasty in older patients using the CCP database found no significant benefit with thrombolysis using a 30 day end point (OR 1.01, 95\% CI 0.94 to 1.09 ) compared to primary angioplasty (OR $0.79,95 \%$ CI 0.66 to 0.94 ). However, at one year there was a significant survival advantage with both fibrinolytic treatment (OR $0.84,95 \%$ CI 0.79 to 0.89 ) and primary angioplasty (OR $0.71,95 \%$ CI 0.61 to 0.83$).{ }^{15}$

The results of landmark randomised controlled trials, metaanalysis, and other recent observational studies comparing fibrinolytics to placebo within an elderly population appear to be consistent: a decreasing relative risk with fibrinolysis, but significant absolute mortality reductions caused by the higher risk adverse outcome from myocardial infarction in older age groups. While age is the single greatest predictor of 30 day mortality from acute $\mathrm{MI},{ }^{16}$ the outcome following fibrinolytic administration is dependent on several other factors which should influence clinical decision making and the interpretation of the broad conclusion reached by Thiemann and colleagues. ${ }^{2}$ Time to presentation is a critical factor. When given within the first hour, mortality reduction has been reported to be up to $50 \%^{34^{12}{ }^{17} 18}$ with progressive loss of benefit and an increase in the rate of myocardial rupture with delay of treatment. ${ }^{3}$ According to meta-analysis of nine fibrinolytic trials, patients with LBBB and those with anterior MI

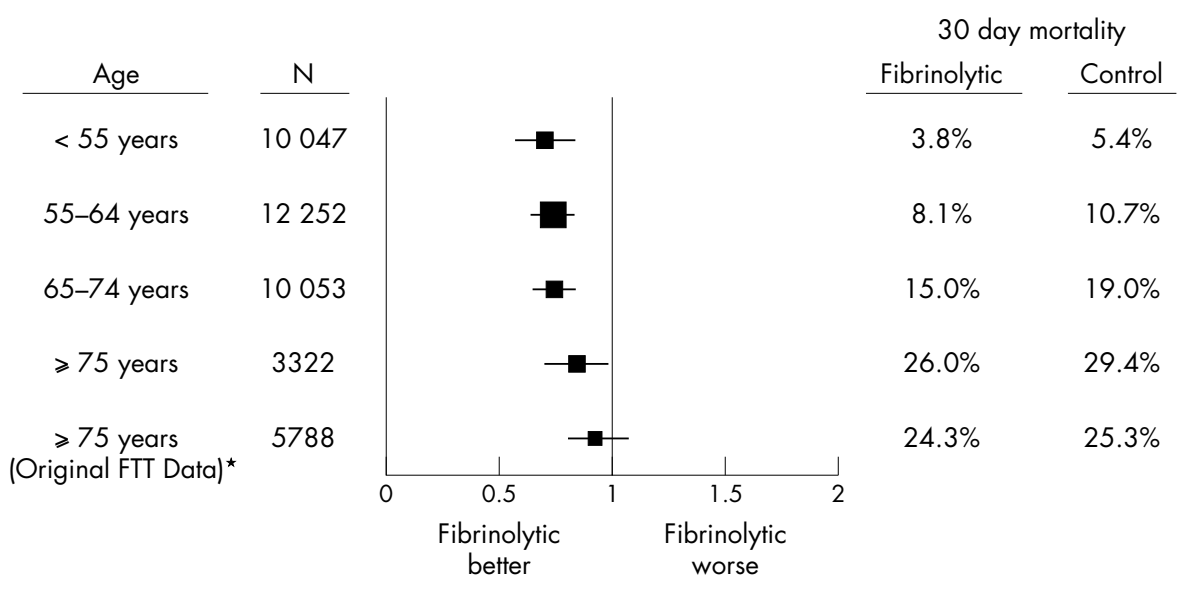

Figure 2 Revised FTT data: patients randomised with proven indications for thrombolysis (that is, ST elevation, new bundle branch block, within 12 hours onset). Excludes patients presenting > 12 hours, with normal ECG, with only T wave inversion or ST depression which were included in the original FTT meta-analysis. (H White, personal communication.) *Original FTT data. ${ }^{12}$ 


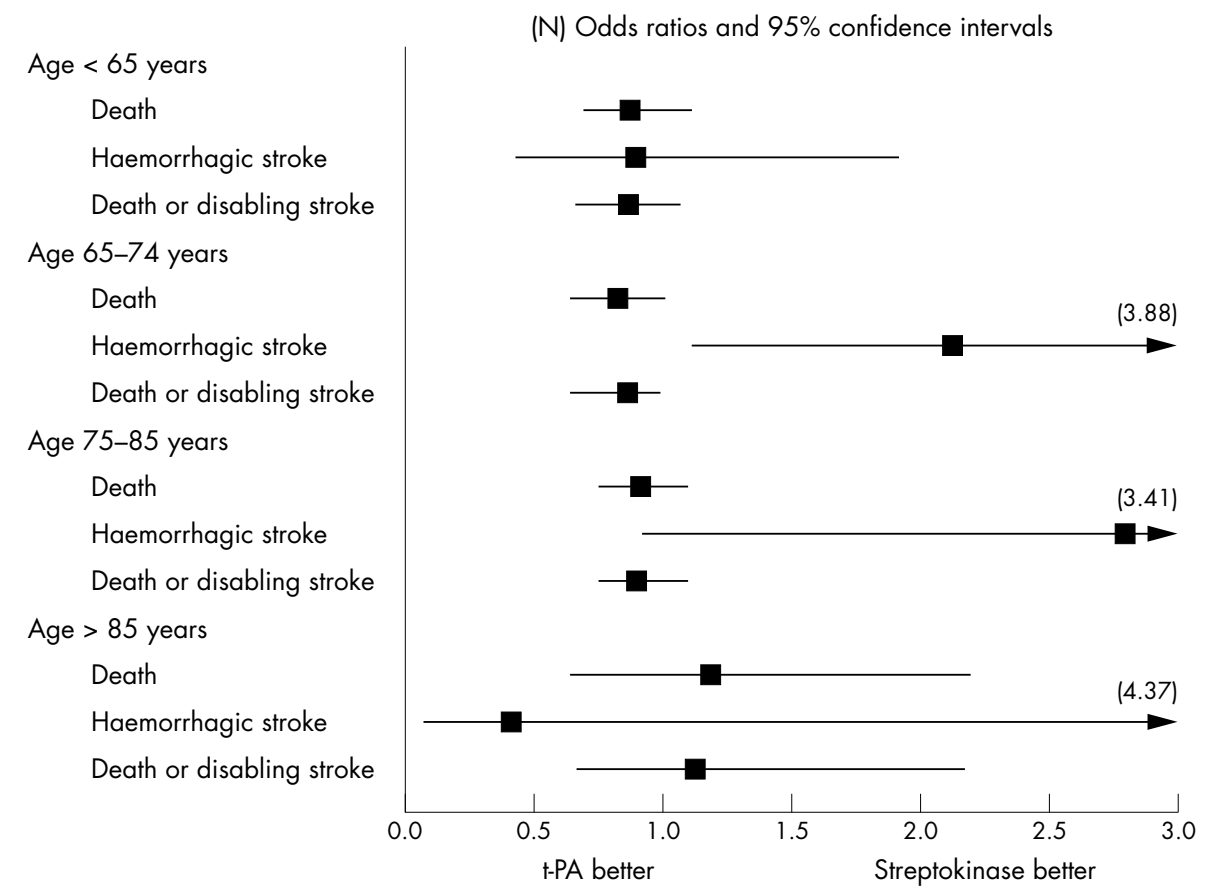

Figure 3 Odds ratios and 95\% confidence intervals for the risk of death, haemorrhagic stroke, and death or disabling stroke at 30 days: treatment with accelerated tissue plasminogen activator (t-PA) and intravenous heparin versus streptokinase and subcutaneous heparin. From White et al. Age and outcome with contemporary thrombolytic therapy results from the GUSTO-I trial. Circulation 1996;94:1826-33 (with permission). ${ }^{13}$

experience substantial benefit compared to those with inferior MI (49 $\vee 37 \vee 8$ lives saved per thousand patients treated respectively). ${ }^{12}$ Infarct size as evidenced by the number of ST segments with elevation has also been shown to correlate with fibrinolytic benefit. ${ }^{319}$ Patients with a presenting systolic blood pressure greater than $175 \mathrm{~mm} \mathrm{Hg},{ }^{12}$ and those with a diastolic blood pressure greater than $110 \mathrm{~mm} \mathrm{Hg}^{20}$ have been shown to have higher rates of intracranial haemorrhage. Female sex has been associated with a poorer outcome from myocardial infarction, ${ }^{16} 2122$ as well as an increase in adverse outcome and a diminishing relative benefit following fibrinolysis with $\mathrm{t}^{-\mathrm{PA}} .^{23}{ }^{24}$

\section{"Weight and age also influence the likelihood of over-anticoagulation with "standard" heparin dosing"}

The observational study by Thiemann and colleagues ${ }^{2}$ included a substantial number of females in the older cohort, many of whom are likely to be of lower body weight. Weight has been shown to be an important consideration with t-PA administration, with an increased risk of bleeding in lower weight $(<60 \mathrm{~kg})$ subjects and a trend toward decreased fibrinolysis in higher weight $(>90 \mathrm{~kg})$ individuals. ${ }^{25}$ Thus selection of the appropriate dose becomes critically important. Weight and age also influence the likelihood of overanticoagulation with "standard" heparin dosing. A J shaped curve for heparin benefit has been previously described using activated partial tissue thromboplastin (aPTT) data from the GUSTO- 1 trial. This trial used heparin bolus of 5000 units followed by 1000 units/hour infusion with an increase to 1200 units/hour for patients weighing over $80 \mathrm{~kg}$. Consistent improvement in outcome was seen with heparin aPTTs between 50-70 seconds. Patients with aPTTs higher than 70 seconds were found to be associated with higher likelihood of mortality, stroke, bleeding, and interestingly re-infarction. Age, weight, and sex were significant predictors of elevated aPTT. Among patients $75-85$ years of age, the average aPTT at 12 hours was 103.4 seconds. ${ }^{13}$ Additionally, there was noted to be a $1 \%$ increase in bleeding for each 10 second increase in the aPTT between $60-100$ seconds. ${ }^{26}$ In recognition of this increased risk, a lower weight adjusted heparin regimen is currently recommended in the American Heart Association/ American College of Cardiology guidelines ${ }^{27}$ for heparin administration with t-PA ( $60 \mathrm{U} / \mathrm{kg}$ bolus; maximum $4000 \mathrm{U}$; $12 \mathrm{U} / \mathrm{kg} /$ hour infusion; maximum $1000 \mathrm{U} / \mathrm{h}$ ) with earlier monitoring of the aPTT. Lack of strict attention to heparin anticoagulation could therefore explain an increased risk in the fibrinolytic group.

\section{RISK OF STROKE}

The risk of stroke has been shown to increase with both t-PA and SK as age increases. ${ }^{40}$ Data from several studies indicate t-PA has been associated with a higher increased risk of stroke relative to SK as age increases. ${ }^{12} 2024{ }^{28}$ However, older patients, those with anterior infarction, higher Killip classification (except Killip class IV), lower blood pressure, and increased heart rate have been shown to have the greatest absolute benefit with accelerated t-PA versus SK. ${ }^{29}$ It is hoped that newer agents may be associated with lower rates of intracranial haemorrhage. Initial clinical trial data with TNK-TPA (tenecteplase) suggests decreased rates of intracranial bleeding, for elderly females $(1.3 \% \vee 2.5 \%, \mathrm{n}=961)$ who are older than 75 years, when compared to t-PA. ${ }^{30}$ These data are particularly encouraging for this high risk subgroup, but further study in this population is needed.

The risk of intracranial haemorrhage associated with fibrinolytic treatment for elderly patients with acute myocardial infarction was recently evaluated from the same CCP database used by Thiemann and colleagues. ${ }^{2}$ Independent risk factors for intracranial haemorrhage were identified as age $>75$ years, female sex, black race, prior stroke, systolic blood pressure $>160 \mathrm{~mm} \mathrm{Hg}$, t-PA versus SK, excessive anticoagulation (international normalised ratio $>4$ ), and below median weight ( $<65 \mathrm{~kg}$ for women, and $<80 \mathrm{~kg}$ for men). ${ }^{31}$

Age in itself should not be a considered a contraindication for fibrinolysis. In contrast to the difficulties of a biased observational sample, many well designed, randomised controlled 
trials provide cogent support for fibrinolytic treatment in the elderly-a decreasing relative benefit, with an absolute gain in lives saved. While the risk for fibrinolysis is increased in this population, so is the risk for death and stroke. Judicious use of heparin is clearly quite important, as is the consideration for either streptokinase or weight adjusted tenecteplase in patients well suited for fibrinolytic treatment, but at particular risk of intracerebral haemorrhage and not eligible for catheter based reperfusion. From the totality of the data currently available, there remains a solid case to use fibrinolytic treatment in elderly patients.

\section{Authors' affiliations}

J M Estess, E J Topol, Department of Cardiovascular Medicine, Cleveland Clinic Foundation, Cleveland, Ohio, USA

\section{REFERENCES}

1 Topol EJ, Califf RM. Thrombolytic therapy for elderly patients [editorial]. N Engl J Med 1992;327:45-7.

2 Thiemann DR, Coresh J, Schulman SP, et al. Lack of benefit for intravenous thrombolysis in patients with myocardial infarction who are older than 75 years. Circulation 2000;101:2239-46.

3 Gruppo Italiano per lo Studio della Streptochinasi nell'Infarcto miocardico (GISSI). Effectiveness of intravenous thrombolytic treatment in acute myocardial infarction. Lancet 1986;i:397-401.

4 Second International Study of Infarct Survival Collaborative Group (ISIS-2). Randomised trial of intravenous streptokinase, oral aspirin, both, or neither among 17,187 cases of suspected acute myocardial infarction. Lancet 1988;ii:349-60

5 Gruppo Italiano per lo Studio della Sopravvivenza nell'Infarcto Miocaridco (GISSI-2). A factorial randomized trial of alteplase versus streptokinase and heparin versus no heparin among 12,490 patients with acute myocardial infarction. Lancet 1990;336:65-71 .

6 Third International Study of Infarct Survival (ISIS-3) Collaborative Group. A randomized trial of streptokinase vs tissue plasminogen activator vs anistreplase and of aspirin plus heparin vs aspirin alone among 41,299 cases of suspected acute myocardial infarction. Lance 1992;339:753-70.

7 The GUSTO Investigators. An international randomized trial comparing four thrombolytic strategies for acute myocardial infarction. $N$ Engl J Med 1993;329:673-82.

8 The Global Use of Strategies to Open Occluded Arteries in Acute Coronary Syndromes Angioplasty Substudy Investigators (GUSTO-Ilb). A clinical trial comparing primary coronary angioplasty with tissue plasminogen activator for acute myocardial infarction. $N$ Engl J Med 1997;336:1621-8.

9 The Global Use of Strategies to Open Occluded Arteries in Acute Coronary Syndromes Angioplasty Substudy Investigators (GUSTO III). A comparison of reteplase with alteplase for acute myocardial infarction. N Engl J Med 1997;337:1 11 18-23.

10 Estudio Multicentrico Estreptoquinasa Republicas de America del Sur (EMERAS) Collaborative Group. Randomized trial of late thrombolysis in patients with suspected acute myocardial infarction. Lancet 1993;342:767-72.

11 LATE Study Group. Late Assessment of thrombolytic efficacy (LATE) study with alteplase 6-24 hours after onset of acute myocardial infarction. Lancet 1993;342:759-66.

12 Fibrinolytic Therapy Trialists Collaborative Group. Indications for fibrinolytic therapy in suspected acute myocardial infarction: collaborative overview of early mortality and major morbidity result from all randomized trials of more than 1000 patients. Lancet $1994 ; 343: 311-22$
13 White HD, Barbash GI, Califf RM, et al for the Gusto-l investigators. Age and outcome with contemporary thrombolytic therapy (results from the GUSTO-I Trial. Circulation 1996;94:1826-33.

14 Stenestrand U, Wallentin L. Thrombolysis is beneficial in elderly acute myocardial infarction patients. J Am Coll Cardiol (in press).

15 Berger AK, Radford M, Wang Y, et al. Thrombolytic therapy in older patients. J Am Coll Cardiol 2000;36:366-74

16 Lee KL, Woodlief LH, Topol EJ, et al, for the GUSTO-I Investigators. Predictors of 30-day mortality in the era of reperfusion for acute myocardial infarction. Results from an international trial of 41021 patients. Circulation 1995;91:1659-68.

17 The EMIP Group. Pre-hospital thrombolytic therapy in patients with suspected acute myocardial infarction. N Engl J Med 1993;329:383-9.

18 Weaver WD, Cerqueira M, Hallstrom AP, et al for the MITI Project Group. Early treatment with thrombolytic therapy: results from the myocardial infarction, triage and intervention pre-hospital trial. JAMA 1993; 270:1211-16.

19 Mauri R, Gasparini M, Barbonaglia L, et al. Prognostic significance of the extent of myocardial injury in acute myocardial infarction treated by streptokinase (the GISSI trial). Am J Cardiol 1989;63:1291-5.

20 Maggioni AP, Franzosi MG, Santoro E, et al, the Gruppo Italiano per lo Studio della Sopravvivenza nell Infarcto Miocardico II (GISSI-2) and the International Study Group. The risk of stroke in patients with acute myocardial infarction after thrombolytic and antithrombotic treatment. $N$ Engl J Med 1992;327:1-6.

21 Malacrida R, Genoni M, Maggioni AP, et al, for the Third Study of Infarct Survival Collaborative Group. A comparison of the early outcome of acute myocardial infarction in women and men. N Engl J Med 1998;338:8-14

22 Weaver WD, White HD, Wilcox RG, et al, for the GUSTO-I Investigators. Comparisons of characteristics and outcomes among women and men with acute myocardial infarction treated with thrombolytic therapy. JAMA 1996;275:777-82.

23 Gurwitz JH, Gore JM, Goldberg R, et al. Risk for intracrania hemorrhage after tissue plasminogen activator treatment for acute myocardial infarction. Ann Intern Med 1998;129:597-604.

24 Angeja BG, Rundle AC, Gurwitz JH, et al for the Participants in the National Registry of Myocardial Infarction 2. Death or nonfatal stroke in patients with acute myocardial infarction treated with tissue plasminogen activator. Am J Cardiol 2001;87:627-30.

25 Califf RM, Topol EJ, Stump D, et al, and the TAMI Study Group. Hemorrhagic complications associated with the use of intravenous tissue plasminogen activator in treatment of acute myocardial infarction. Am J Med 1988;85:353-9.

26 Granger CB, Hirsh J, Califf RM, et al for the GUSTO - I Investigators. Activated partial thromboplastin time and outcome after thrombolytic therapy for acute myocardial infarction. Circulation 1996;93:870-8

27 Ryan TJ, Antman EM, Brooks NH, et al. 1999 update: ACC/AHA guidelines for the management of patients with acute myocardial infarction: a report of the American College of Cardiology/American Heart Association task force on practice guidelines (committee on management of acute myocardial infarction). J Am Coll Cardiol 1999:34:890-911.

28 Simoons ML, Maggioni AP, Knatterud G, et al. Individual risk assessment for intracranial hemorrhage during thrombolytic therapy Lancet 1993;342:1523-8.

29 Califf RM, Woodlief L, Harrell FE, et al, for the GUSTO-I Investigators. Selection of thrombolytic therapy for individual patients: development of a clinical model. Am Heart J 1997;133:630-9.

30 Barron HV, Fox NL, Berioli S, et al. Comparison of intracranial hemorrhage rates in patients treated with rt-PA and TNK-tPA: impact of gender, age and low body weight. Circulation 1999;100(suppl I):I-1.

31 Brass LM, Lichtman JH, Wang Y, et al. Intracranial hemorrhage associated with thrombolytic therapy for elderly patients with acute myocardial infarction. Results from the cooperative cardiovascular project. Stroke 2000;31:1802-11 